\title{
Research Crowdfunding and Scholarly Communication: A Case Study of Three Campaigns
}

\author{
Darren Chase \\ Stony Brook University \\ darren.chase@stonybrook.edu
}

\author{
Dana Haugh \\ Yale University \\ dana.haugh@yale.edu
}

\author{
Victoria Pilato \\ Stony Brook University \\ victoria.pilato@stonybrook.edu
}

\begin{abstract}
Crowdfunding leverages the opportunities of online social networks to share ideas and connect individuals by seeking small donations from a large number of supporters in order to complete a project or develop a product. Research crowdfunding is emerging as a dynamic alternative or supplement to grant-funded research, particularly for low-cost research, researchers at institutions without strong traditions of grants-funded research, and high-risk or unconventional research with few or no sponsors. For some researchers, crowdfunding enables new and novel collaborations between researchers, entrepreneurs, artists, social and environmental activists, as well as facilitating unexpected uses and expressions of research.
\end{abstract}

Through the lens of three qualitative crowdfunding campaign studies this article explores how crowdfunding conventions and platforms influence and impact the way research is used, communicated, shared, and in some cases performed. Successful crowdfunding relies on engagement and audience support -- higher levels of support include exclusive affordances, including opportunities to participate in events, acknowledgement in publications, and access to the researchers via online or in-person meetings. Crowdfunding platforms offer researchers the framework to appeal for support and communicate the details and progress of their research in a personal, narrative style, often utilizing video and social networks. This article will examine the 
new opportunities for communicating, sharing, and using research that crowdfunding facilitates through a case study of three crowdfunding campaigns.

Keywords: crowdfunding, scholarly communication, higher education, research, libraries, information science, open science, open access

\section{Implications for Practice}

1. Crowdfunding can play a positive role in promoting and facilitating open science and open access.

2. Research-based crowdfunding fosters connections between researchers and the audience, and makes available to researchers a potentially enthusiastic group of supporters seeking to meaningfully participate in science.

3. Crowdfunding conventions, platforms, and features facilitate new channels of scholarly communication of research activities and outputs, including public lab notes, online discussion, meetups, and creative multimodal scholarship, and presentation of research.

\section{Introduction}

Research crowdfunding is a transformation of traditional grants-funded research (Vachelard, Gambarra-Soares, Augustini, Riul, \& Maracaja-Coutinho, 2017). Crowdfunding is characterized by ongoing interactions between supporters and those seeking funding. The crowdfunded model facilitates connection with an audience of supporters, transparency, accountability, and tangible affordances. It enables supporters to experience the project development process alongside the 
campaign principal investigators. Crowdfunding has grown to include all types of campaigns, including product development, artists/author support, filmmaking, and research.

There are concerns about the ethics of crowdfunding for research. Some concerns come from the researchers themselves and include: possible theft of research, and lack of credibility and loss of funding opportunities from other sources if their campaign does not reach funding, as well as feeling like a failure (Gerber \& Hui, 2013, p. 34:18). Issues raised by academics and backers of crowdfunded research include: how is the money actually being spent (Gerber \& Hui, 2013, p. 34:22), and the credibility of the research since it may not be sanctioned by or representing a university or other scholarly institution (Ingeno, 2013).

To approach understanding of what motivates researchers to seek crowdfunding even at institutions with the highest level of sponsored research, consider this quote from Inside Higher Ed (Ingeno, 2013): “. . . the benefits of crowdfunding [are] twofold . . More "high risk" projects that the government would not regularly invest in can receive funding, and the public can directly engage with the research being produced." Through crowdfunding, researchers are seeking opportunities for pursuing unconventional research, and building mutually beneficial connections with supporters.

While there are clear, meaningful risks and benefits of crowdfunding as a funding model, this case study is focused on whether and how crowdfunding leads to different ways of communicating research. If the traditional research funding and scholarly communication continuum is ill-suited to the conventions of crowdfunding, how are researchers meeting the challenges and opportunities that crowdfunding presents? As described in Research funding in open science (Eisfeld-Reschke, Herb, \& Wenzlaff, 2014): 
Publicly financed research nevertheless does not appear well-suited to crowdfunding in the classic sense: research as a process is lengthy, institutionally anchored, and teambased. It is also expensive. The results of the research process in many disciplines are not immediately 'tangible' — rather they are documented in articles, books, or conference presentations, and more rarely in patents and new products. Researchers are normally not judged or evaluated according to how well they can explain their research to the public (not to mention to their students), but according to how successfully they present themselves to their peers in the academic journals, conferences, and congresses of their respective fields.

\section{Methods}

As a case study, the goal of this paper is to examine and describe three research crowdfunding campaigns as a method for understanding the key qualities and features of crowdfunding, its role in research and influence on scholarly communication. The examination is through a set of research questions, listed below.

This paper uses data derived from examination of the campaigns' platforms, overviews, goals, updates, comments, outcomes, social media integration, and related resources.

\subsection{Research questions}

The campaign case studies were performed through the lens of the following research questions:

- What is the campaign and what are its goals?

- Who are the campaign principals?

- What are the interactions between the campaign principals and supporters? 
- What affordances are offered to campaign supporters?

- How and where is crowdfunded research/campaign outcomes shared, used and communicated?

- Was the campaign funding goal met?

\title{
3. Case Studies
}

\subsection{Achieving food sovereignty with edible insects: Breaking the cycle of poverty and malnutrition}

\begin{abstract}
About
The Achieving food sovereignty with edible insects: Breaking the cycle of poverty and malnutrition campaign on Experiment sought to raise the remainder of funds needed to cultivate a food source for the shea caterpillar, a nutritious food of the people in Burkino Faso, West Africa that currently are only available for a short time each year. The goal is to make it possible for the people of this region to rear the caterpillar as they do small livestock to ultimately "...take control of their food and income." The campaigners hope to do this by producing an artificial feed for the caterpillars based on local produce (Payne, Badolo, \& Dobermann, 2017, About this Project). The project was started about a year prior to the Experiment campaign by three researchers (the campaigners): Charlotte Payne, Athanase Badolo, and Darja Dobermann. The three met by the end of 2015. They were on location in the field doing studies and analysis, figuring out their needs, and what courses of action to take by the end of 2016 (Payne, et al., 2017, Team bio). The team competed at BCFN YES! (Barilla Center for Food and Nutrition Young Earth Solutions), “an international competition for young researchers from all over the
\end{abstract}


world ... with the aim of rewarding the best ideas about food and sustainability," in 2016 (Barilla Center for Food and Nutrition, 2016).

Competing in BCFN YES! led to their presentation at the 7th International Forum on Food and Nutrition in Milan on December 1, 2016. This presentation landed them a 8000EUR award from BCFN towards their research. The research team already knew they required 10000 EUR to accomplish their goals so an Experiment campaign was created January, 2017 for the last 2000 EUR. Campaigns in Experiment are organized by topic, or discipline, as seen in Fig. 1. This campaign was assigned two topics; the first, Biology and the second, Social Science. All campaigns in Experiment are given a Digital Object Identifier, which provides the campaign with a permanent number that can be searched online; this campaign was assigned DOI:

$10.18258 / 8880$.

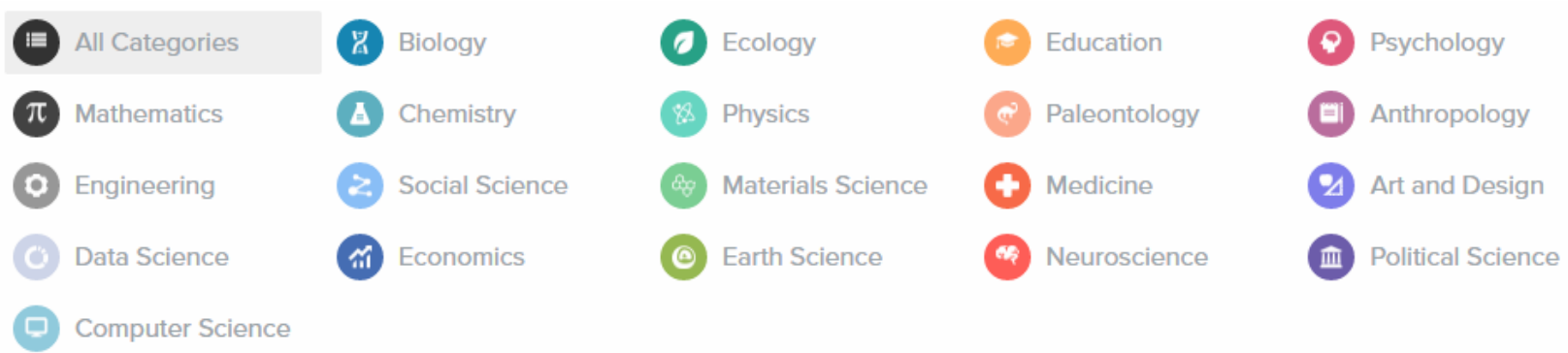

Fig 1. Topics listed on the Experiment website

\section{Campaign principals}

The following section is summarized from the homepage of the campaign in the section, "Meet the Team" (Payne, et al., 2017).

Payne, Badolo, and Dobermann met in mid to late 2015 because of their similar interests in edible insects. Charlotte Payne is a PhD student affiliated with Conservation Science Group, Department of Zoology, University of Cambridge. Payne's interests are in 
conservation science, after first studying and researching human origins where she switched her focus to food sustainability. Payne grew interested in the importance of insects as food while "working on insectivory in chimpanzees" (Payne, 2017). Athanase Badolo is an Associate Professor affiliated with Laboratoire d'Entomologie Fondamentale et Appliquée, Université Ouaga I Pr Joseph Ki-Zerbo. Badolo is interested in biology and works in entomology and entomophagy and believes eating insects is a way to get protein in the diet at little cost to the earth's resources. Lastly, Darja Dobermann is a $\mathrm{PhD}$ researcher affiliated with Rothamsted Research and University of Nottingham.

Dobermann began working in developmental psychology and found her way into studying nutrition, encompassing her other skills in agriculture, biochemistry, biology, and entomology.

\section{Budget}
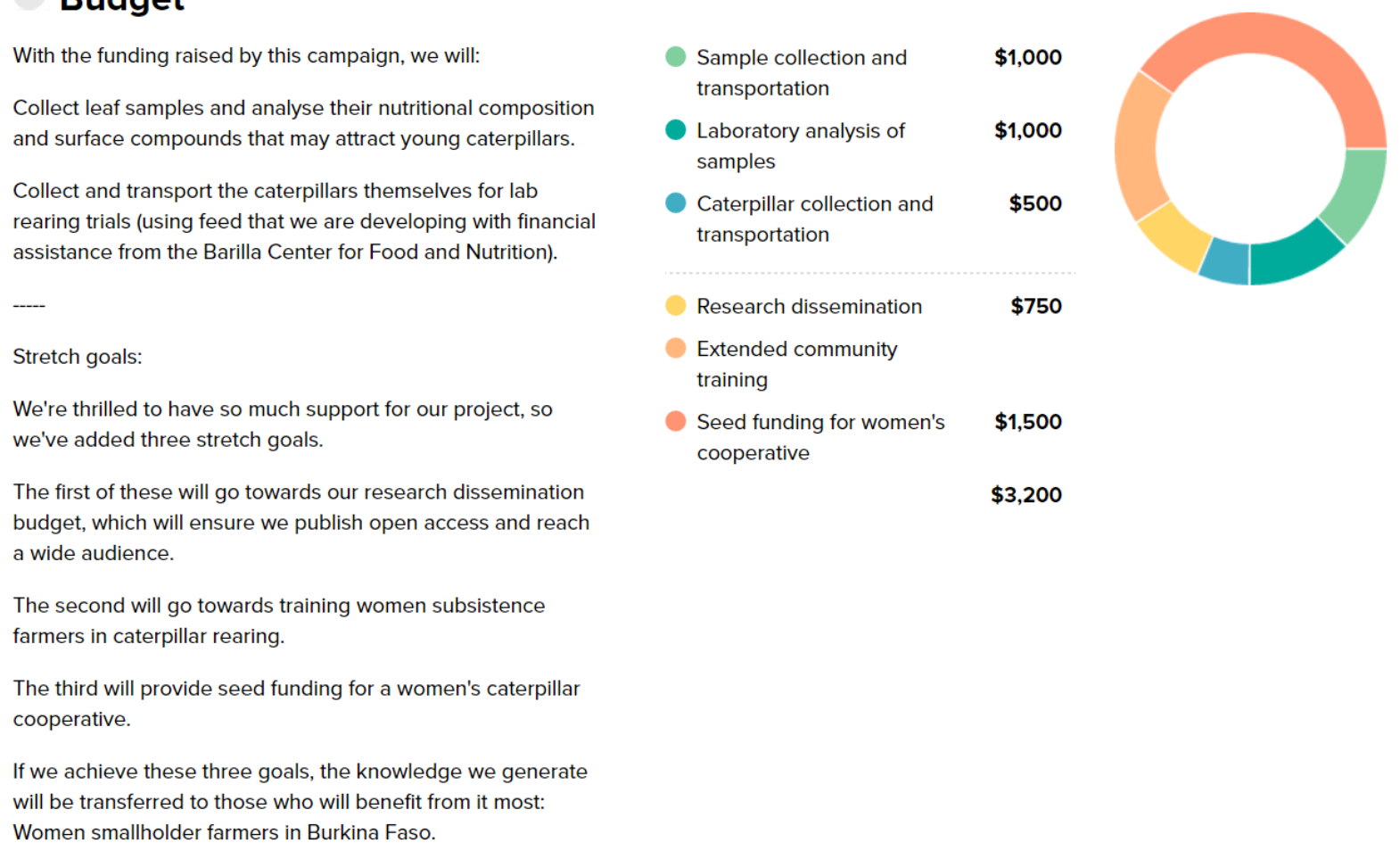


\section{Fig. 2 Achieving Food Sovereignty campaign budget breakdown on Experiment}

\section{Campaign affordances and interactions with supporters}

Payne, Badolo, and Dobermann provide detailed information about their campaign in the Overview section of their campaign website on Experiment. The team provide hyperlinks in the text for resources to back-up their statements. The research team are clear about their goals and provide a chart on how the money will be spent [Fig. 2]. They also provided stretch goals when funding went over their goal. Besides text there are many videos and images. A video that summarizes the research and mentions the backing of BCFN is offered on the homepage of the campaign. Biographies are presented for each researcher as well as an endorsement from a colleague, Peter Scarborough, Associate Professor, University of Oxford. An endorsement from someone at a research institution provides a sort of peer-review in place of institutional backing in the traditional grant program sense. It is also a requirement for campaigns dealing with animals or human subjects (Experiment, Researcher Guide/ Additional criteria for academic scientists). The Discussion section of the campaign was used first by a backer, simply wishing

them luck. The discussions in this section consist of casual correspondence and is not currently being used for discussing the research, for the most part.

The research team utilizes the Lab Notes section in Experiment, which keeps the audience easily involved and updated. The Lab Notes tell their story, and telling a story is proven to be an important step in having a successful campaign (Ibrahim, Symmons, \& Lupiáñez, n.d., Getting specific). There were nine lab notes provided by the research team as of April, 2017. Three of which came after the campaign was funded. Most of the lab notes consist of text, links to blog posts, images, and videos. Many images and stories about the community the research could benefit are included. Backers are aware of the updates through email. Non-backers and 
backers alike can find information about the campaign and the research on the team's individual social media feeds, YouTube and Vimeo videos, as well as Payne's blog, all of which can be accessed through their Experiment campaign.

The Achieving Food Sovereignty... campaign on Experiment gained recognition shortly after being launched. As of April, 2017, the campaign was shared on Facebook 56 times and posted about twice [See Fig. 3 and Fig. 4]. It was posted on Twitter at least 5 times and retweeted, but the retweets were not counted for this paper. The BBC's World Service, CrowdScience, did a story on edible insects and interviewed one of the campaign researchers (Jagatia, 2017). 


\section{David Michaels}

March 3. 0

Another great cause you can support. Helping to end poverty and hunger ... through caterpillars!

I had the pleasure and honor of editing this video, as well as helped with the script a bit.

Great people who really want to make a positive difference in the world. Those are the kinds of people I want to work with. I support them.

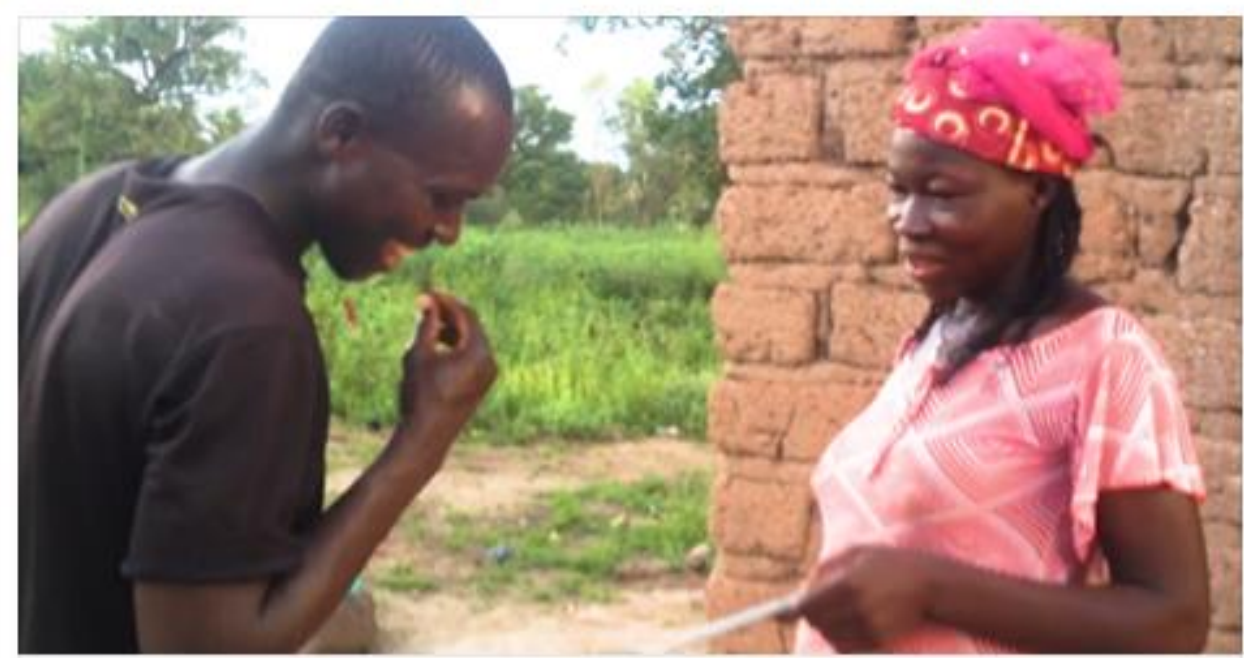

Achieving food sovereignty with edible insects: Breaking the cycle of poverty and malnutrition

Food insecurity and environmental degradation disproportionately affect the world's poorest. Our project tackles this. We will develop a protocol for farmers...

EXPERIMENT.COM

$100_{3}$

Like Comment $\Rightarrow$ Share

Fig. 3: A Facebook post from David Michaels who helped create the video for the campaign 


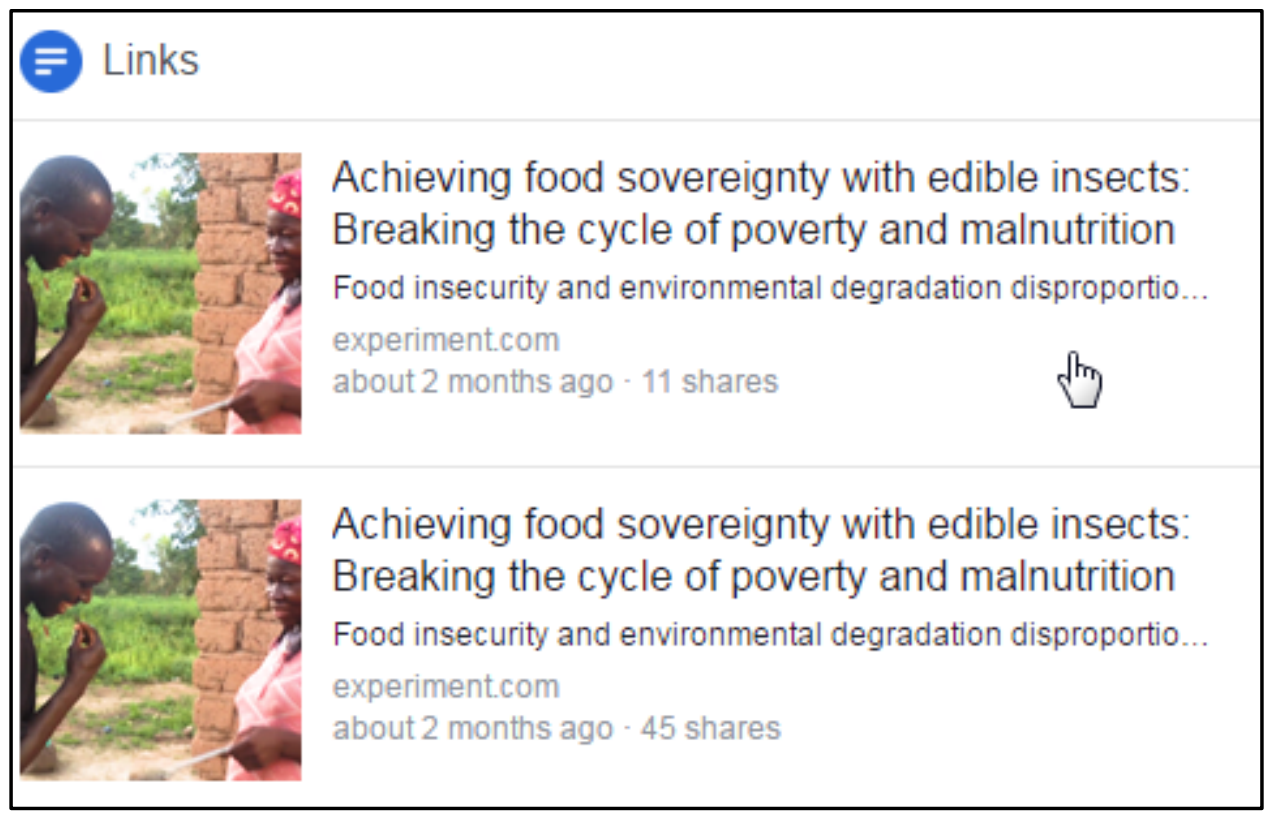

Fig. 4: Facebook results for search of campaign shows 56 shares of the platform

Analysis \& Results

The three month campaign was successfully funded on April 11, 2017, and continued to gain funds until the end of the campaign resulting in $\$ 3,107$ as of April 27, 2017, or being $124 \%$ funded. Experiment does not support a Kickstarter type reward system for backing campaigns. The researchers are to stay in contact with the backers and update them on their research in the form of Lab Notes and Discussion, two sections of an Experiment campaign. The researchers fulfilled these requirements.

The research lends itself well to this kind of funding because of the recognizable nature of the components: people and insects. Images for this type of research, even though some consist of caterpillars as a possible food source, are not novel, or hard to understand. They lend themselves to storytelling. In fact, the presentation at BCFN YES! started as a fairy tale, comparing the shea caterpillar to a knight. Also, "edible insects" is not a new concept. Whether it has been reported on as an exotic culinary experience, or, as in this campaign, a possible source 
of sustainable nutrition, it has made its presence on social media newsfeeds. An article in Fortune by Laurie Tarkan in 2015 entitled, Why Start-ups want you to eat bugs, had 403 shares on Facebook at the time of writing this article (Tarkan, 2015).

The campaigners for Achieving Food Sovereignty ... utilized the openness of the crowdfunded model. Some ways they did this was to make it easy to directly contact them as well as provide all of their social media accounts and personal websites, which offer a view into their history of interests and research relating to their campaign. If interested, a potential backer could find that the researchers are serious, and have been heavily involved, in this type of work for some time proceeding the birth of their campaign.

\title{
3.2 SINES
}

\author{
About \\ SINES: An LSD Brain Wave and Sound Art Hackathon is a campaign for staging an interactive \\ "hackathon" event that brings together sound artists, technologist, and neuroscientists for \\ intensive collaboration in the creation and performance of new, dynamic representations of the \\ brain under the effects of the psychedelic drug lysergic acid diethylamide (LSD) [see Fig 5]. \\ The hackathon incorporated the brain wave data recorded in Dr. Robin Carhart-Harris's \\ laboratory, combined with the expertise and resources of sound artists, neuroscientists and data \\ analysts in order to "explore the brain waves in novel ways and to create mind altering \\ soundscapes, aural installations, and musical compositions from extracted features of the \\ psychedelic brain data" (Bedder, Carhart-Harris, Lorenz, Marcus, \& Stratton, 2017).
} From the campaign overview (Bedder, et al., 2017): 
The hackathon will be a two-day event over the weekend of the 18/19th March in Central London (West Central) with Dr. Carhart-Harris introducing the dataset and research. The interdisciplinary 5 teams (consisting of 1 sound artist grouped with 2-4

neuroscientist/data scientists) will then spend the remainder of the time working on their responses to the brief. A concert-like presentation of the created work will conclude the event in the evening of 19th March (6:30 pm). 


\section{An LSD brain wave and sound art hackathon}

\section{Campaign Complete. This project has ended on March 19, 2017. No more contributions can be made.}
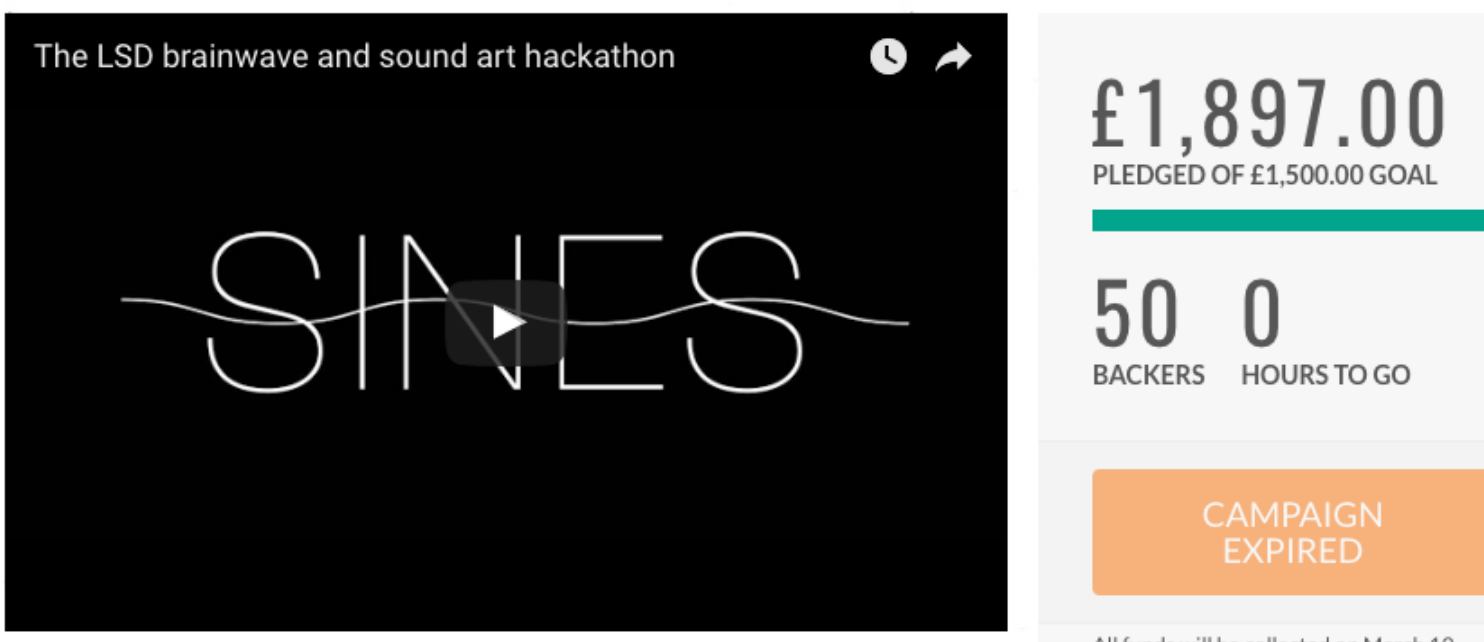

All funds will be collected on March 19 2017.

Fig. 5: SINES campaign page on the crowdfunding site Crowd.Science.

\section{Campaign principals}

The campaign principals are the AXNS Collective, Dr. Robin Carhart-Harris and Music Hackspace. AXNS Collective is "not-for-profit, curatorial collective that explores intersections between art, neuroscience and technology" comprised of Rachel Bedder, a computational neuroscientist, Romy Lorenz, a cognitive neuroscientist and neuro-technologist; Miranda Marcus, a graphic designer and digital anthropologist; and Rachel Stratton, an art historian and curator. The collective programme panel discussions, curate exhibitions, carry out workshops in museums and schools, and commission collaborative projects between artists, neuroscientists and 
technologist (Bedder, et al., 2017). Since 2012 AXNS was supported by various funders, amongst them are the Wellcome Trust, the Arts Council, and the Wates Foundation (Marcus, 2013). For the SINES campaign, AXNS Collective partnered with Dr. Robin Carhart-Harris, Head of Psychedelic Research in the Division of Brain Sciences at Imperial College London. Dr. Carhart-Harris, "studies the brain effects of LSD, psilocybin and MDMA using multi-modal neuroimaging techniques. Most recently he has completed the first phase of a clinical trial looking at the potential of psilocybin to treat treatment-resistant depression" (Bedder, et al., 2017).

Music Hackspace is a London-based community that includes musicians, artists and technologists. It sponsors weekly open events featuring "new content in artist presentations, demos, workshops, premieres and events engaging with sound, music, art, music technology, new instruments, computer music, electronics, and all kinds of noisy ideas" (Music Hackspace, About Us).

\section{Fundraising goal}

The campaign exceeded its fundraising goal. The campaign began February 9, 2017 and ended March 19, 2017. The campaign fundraising goal was $£ 1500.00$, and $£ 1897.00$ was raised (Bedder, et al., 2017). 
AXNS Collective

15 March $\cdot \Theta$

Can you help us hit $£ 1900 ;-$ - nice perks left! https://crowd.science/ .../lsd-brainwave-and-sound-art-hackath...

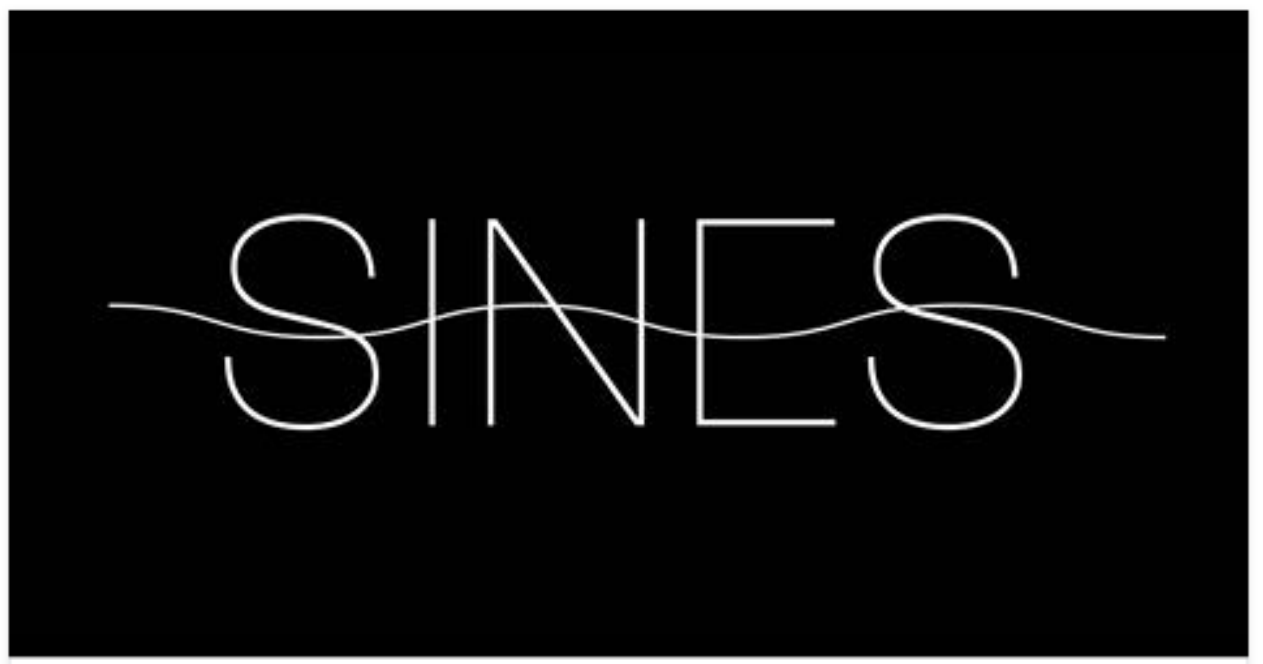

An LSD brain wave and sound art hackathon Crowd.Science

How can a sine wave link neuroscientists and sound artists? In 2012, Imperial College London were awarded a research grant from the UK government's...

CROWD.SCIENCE
Lìke
Comment
Share

Fig. 6: A Facebook post from the AXNS Collective page promoting the crowdfunding campaign.

Campaign affordances and interactions with supporters

The interaction between the campaign principals and supporters through the crowdfunding platform is an essential lead to the hackathon itself. The campaign overview includes a video introduction describing the campaign, introducing the principal investigators, illustrating the synergistic and creative value of the event, and inviting support and participation. 
The invitation to participate, both for creators/performers and audience members, was a significant aspect of the campaign, and well-suited to crowdfunding conventions and potentials.

Campaign supporters were offered affordances through a tiered rewards system that included concert tickets to the hackathon, a digital recording of the hackathon, and "1-hour long private EEG session with neuroscientist Romy Lorenz at Imperial College London” (Bedder, et al., 2017).

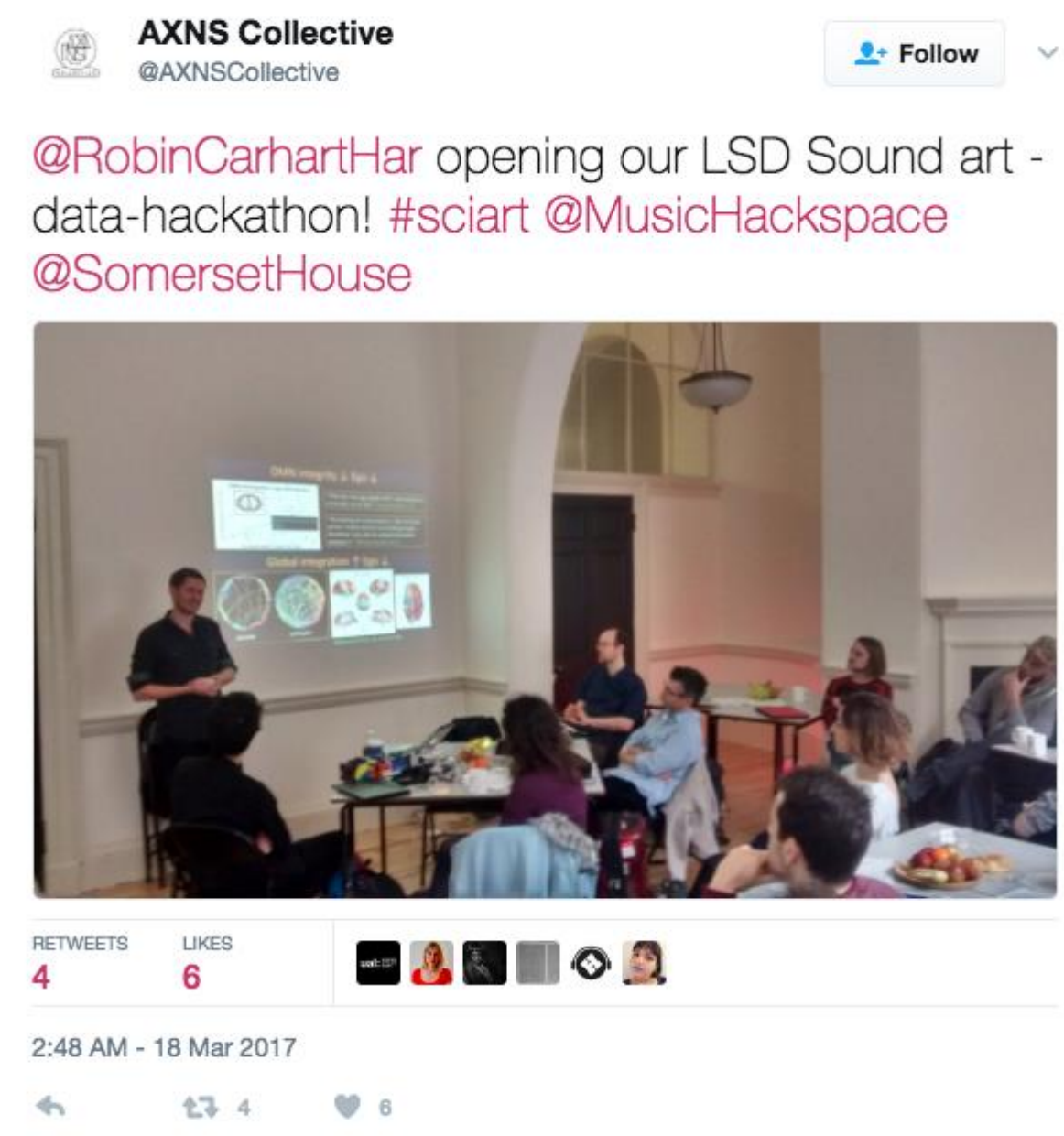

Fig. 7: A twitter post from the SINES hackathon event showing campaign principal Dr. Robin Carhart-Harris. 


\section{Communicating and sharing research}

How research is communicated is the force animating the campaign and hackathon. Dr. Carhart-Harris states in the introductory video (Crowd.Science, 2017), "One of the challenges of this research is how to communicate to the general public how these drugs are working in the brain. How can we display our data in a way that is meaningful to people?" He goes on to describe the static image output of laboratory brain imaging work as it appears in conventional scholarly communication channels such as peer-reviewed journal articles and conference proceedings (including his own research article in The Lancet that is linked within the campaign overview). Dr. Carhart-Harris states (Crowd.Science, 2017) that static images do not convey the reality of "how these drugs are changing the brain":

Because biological systems aren't static. They're characteristically dynamic. They change and they're always moving. One of the challenges is to try and find a way to display our data, to communicate our data, that is truer to that dynamic reality.

The principals used twitter and facebook posts to promote the campaign and hackathon, and contextualize the research into the goals of the campaign and activities of the hackathon [see Fig. 5 and Fig. 6].

\section{Analysis and results}

SINES is an interdisciplinary campaign uniquely and effectively served by the underlying sociality of research crowdfunding. A hackathon is an intensive design and programming event; it's a well-known practice in software design, but not a common method for sharing or incorporating research at biomedical conferences, meetings, and symposia. The SINES campaign both invited supporters and participants to the hackathon. The engine that drives crowdfunding is 
audience. Crowdfunding offers individuals the opportunity to support and participate in projects that connect with their interests and passions, while offering researchers the opportunity to pursue non-traditional, creative activities and strategies for using, sharing, and communicating research output.

\title{
3.3 The Golden-winged Warbler Migration Project
}

\begin{abstract}
About
The Golden-winged warbler migration project attempts to better understand the migratory pattern and breeding ranges of the aforementioned avians by tracking their journey through the use of small geolocators. These geolocators, weighing less than 0.5 grams, are fitted to a select few songbirds and left on for a full year in order to monitor the bird's migration. The geolocators are similar to tiny bird backpacks with leg-loop harnesses; a recent study has concluded that there is no significant effect on migratory ecology for birds wearing these locators (Peterson, Streby, Kramer, Lehman, Buehler, \& Andersen, 2015).
\end{abstract}




\title{
Join the Journey: Golden- winged Warbler Migration
}

\author{
By Anna Buckardt and Amber Roth
}

Backed by Nan Buckardt, Possibility Place Nursery, Inc., George Balogh, Marge Cahak Gibson, John Pollinger, Debra Buckardt, Kris Perlberg, Mae Buckley, Kevyn Juneau, April Williamson, and $\mathbf{4 3}$ other backers

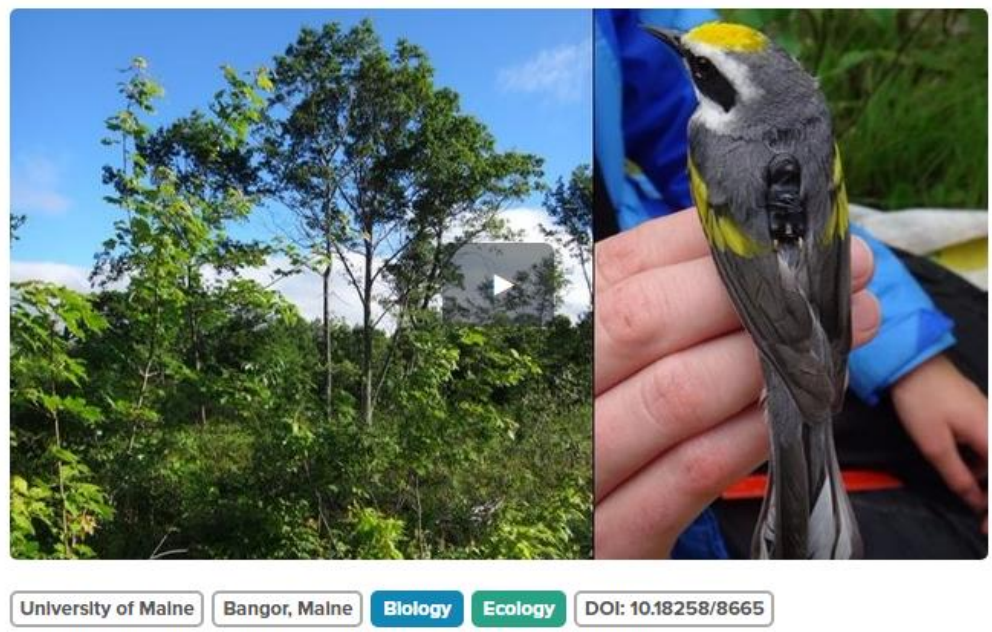

\section{$\$ 3,911$}

Raised

\section{$148 \%$}

Funded on $3 / 18 / 17$

Successfully Funded

? How does this work?

Fig. 8: Golden-winged Warbler Migration project on Experiment

The information gathered from these journeys will be used "to encourage and inform effective conservation strategies ... [highlighting] which forest habitats and specific locations are of highest conservation priority” (Buckardt \& Roth, 2017, Ask the Scientists, para. 1). According to researcher Anna Buckardt, golden-winged warblers have experienced a "steep population decline in the last four years and their population size has reduced by $66 \%$ since the 1970s" (Video file, February 19, 2017). They are the fastest declining forest bird species in North America and conservation of their breeding and winter habitats is of utmost importance to their survival (Video file, February 19, 2017). 


\section{Campaign Principals}

The campaign team consists of two researchers: Anna Buckardt and Amber Roth. Anna Buckardt is a M.S. Candidate of Wildlife Ecology at the University of Maine and began field work for her thesis in the spring and summer of 2016. The campaign's inception is partially a product of her thesis research, which focuses on "bird response to young forest habitat management on private properties in Wisconsin, and how best to involve landowners in conservation and wildlife monitoring efforts" (Buckardt \& Roth, 2017, Meet the Team para. 23).

Her co-researcher, Amber Roth, is an Assistant Professor of Forest Wildlife Management at the University of Maine. Amber has been involved with many aspects of Golden-winged Warbler research and conservation planning for two decades and her current research program also includes habitat evaluation and migration for the American Woodcock (Buckardt \& Roth, 2017, Meet the Team para. 4).

\section{Goals \& Funding}

The funds generated from the Experiment campaign enable the researchers to retrieve 28 geolocators that were fitted on Wisconsin-based Golden-winged warblers during 2016. The retrieval process will begin May 15th and continue until July 1, 2017 (Buckardt \& Roth, 2017, Budget para. 1). As shown in Figure 8, the initial campaign goal totaled $\$ 2,625$, allotting $\$ 1,575$ for mileage to the study sites and $\$ 1,050$ for 90 days of housing. The researchers also set stretch goals, with every $\$ 250$ over the initial goal equaling one new geolocator for the $2017-2018$ year (Buckardt \& Roth, 2017, Budget para. 2). According to Amber Roth, two of the main reasons for crowdfunding this research include "supplement[ing] other funding to expand our research 
capacity" and "encouraging the involvement of non-traditional partners in research" (A. Roth, personal communication, August 16, 2017) [See Appendix 5.3]. Anna Buckhardt goes on to explain,

One particular grant to fund my summer field season was not as successful as we had hoped, and we were running short on time to submit more grant proposals. I saw crowdfunding as an opportunity for me to raise the funds necessary to support my field work in a relatively short amount of time. The original goal of the crowdfunding page was to reach the bare minimum funds needed to continue my work. Thankfully it was successful enough to cover the basic needs plus some, resulting in an expansion of the research (A. Buckhardt, personal communication, August 17, 2017) [See Appendix 5.3].

\section{Budget}

Light-level geolocators track long-distance animal movements and can be used to determine broad-scale habitat use. These devices are deployed for a year. The birds must be relocated and recaptured to remove their geolocators and retrieve the data. Twenty-eight geolocators were deployed on Goldenwinged Warblers breeding in Wisconsin in 2016. The funds we've raised so far will help me retrieve all of the geolocators, in Wisconsin between May 15 and July 1.

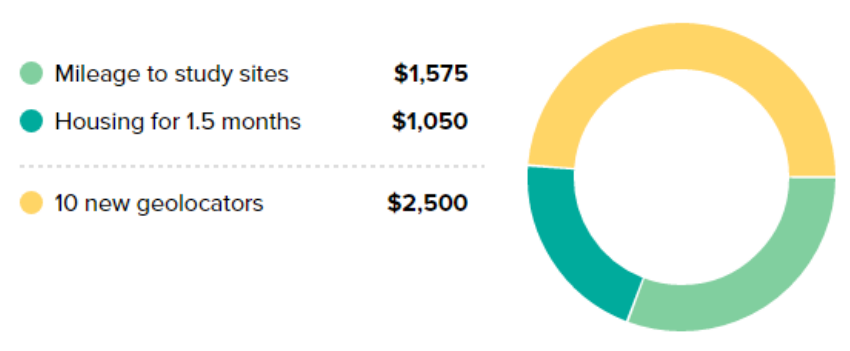

Stretch goal funds will be used to purchase and deploy new geolocators in $\mathbf{2 0 1 7}$ on recaptured Golden-wings. For every $\$ 250$ raised we will track one bird for a second consecutive year of their migratory journey to see if the habitats they use and the routes they take differ between years.

\section{Fig. 9: Golden-winged Warbler project budget breakdown on Experiment}

According to Buckardt's Lab Note \#2, the 30-day campaign was launched mid-February 2017 and met its initial funding goal in 9 days. The remaining 21 days gave the researchers a chance to raise funds for additional geolocators to track migration patterns on a Golden-wing for a second consecutive year (Buckardt \& Roth, 2017, Lab Note \#2 para. 1). The campaign 
concluded on March 18, 2017, raising \$3,911 for the project (Buckardt \& Roth, 2017). The additional funds support roughly 5 new geolocators for a second year of tracking.

The campaign had 59 backers with an average donation of \$66.29 (Buckardt \& Roth, 2017, Project Backers). Amber Roth commented "Crowdfunding provided a mode for people in our networks to easily contribute to our research. We received many donations from friends, colleagues, and family. The nice thing about a crowdfunding platform with regular supporters was that we were able to attract these "regulars" as well" (A. Roth, personal communication, August 16, 2017) [See Appendix 5.3]. Approximately $70 \%$ of backers created Experiment accounts during February or March 2017. Of the 70\%, only one had supported an additional campaign, suggesting a majority of Golden-winged Warbler backers were petitioned to join the platform in order to support this specific project.

\section{Campaign affordances and interactions with supporters}

The campaign does not offer any formal or tiered affordances for backers. Instead, the researchers promise to share their findings once they begin collecting data. Lack of affordances does not appear to have had an effect on this project, as the initial monetary goal was reached well under the the campaign duration, and the project continued to receive backers $(\$ 1,286)$ until its formal conclusion in March (Buckardt \& Roth, 2017).

There are currently two "Lab Notes" available for viewing. The first, published February 22, 2017, is an informational YouTube video about some of the winter habitat research Amber Roth conducted on Golden-winged Warblers while visiting Nicaragua in January 2017 (Lab note $\# 1,2017)$. The second, published just three days later, is a video clip of Anna Buckardt thanking backers for helping fully fund the project in just 9 days (Buckardt, 2017, Lab note \#2).

Buckhardt comments "Working on this crowdfunding page helped me to convey my research in 
the simplest and most widely digestible terms, which really helped me grasp it better myself. I also got to expand my skills with video creation and editing, which was a lengthy but valuable process. It took many more hours of preparation and editing than I initially anticipated, but it clearly paid off” (A. Buckhardt, personal communication, August 17, 2017) [See Appendix 5.3].

Anna Buckardt $>$ Lake Cook Audubon

February $16 \cdot 0$

$\mathrm{Hi}$, My name is Anna Buckardt, I grew up birding in Lake County. Now I'm a graduate student at the University of Maine and I study declining forest birds and habitat management. My research focuses on Golden-winged Warblers and American Woodcock. Please check out my crowdfunding page to learn more about my research and consider joining the journey. Your contributions to this research will be helping to increase the effectiveness of conservation efforts for these wonderful birds.

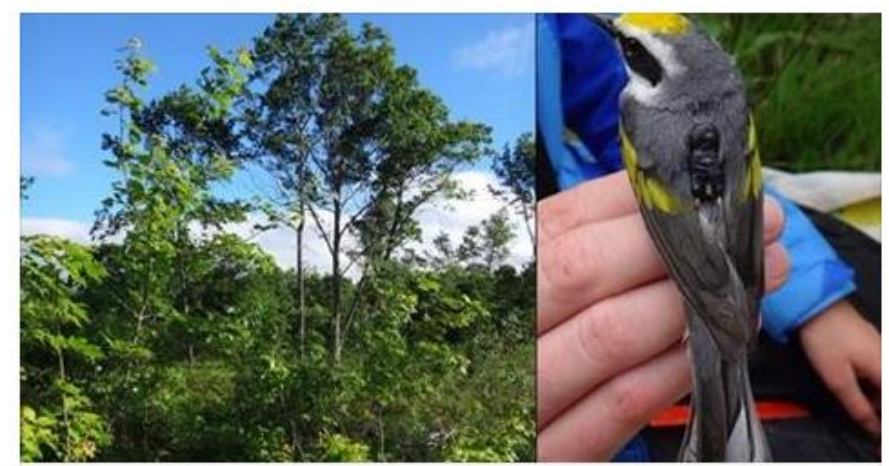

Join the Journey: Golden-winged Warbler Migration Golden-winged Warblers are one of North America's fastest declining forest bird species. To reverse this decline, it is important to conserve the breeding (US/Canada) and winter (Latin America) habitats of this migratory songbird. We. EXPERIMENT.COM

Fig. 10: Facebook status update by Anna Buckardt

Anna Buckhardt promoted her campaign on Facebook, creating a series of posts encouraging Facebook friends and followers to support the project (Buckardt, 2017). She also targeted specific groups interested in habitat conservation and birding, like the "Lake Cook Audubon" Facebook group (Buckardt, 2017). Additionally, a Facebook group called "Kemp Natural Resources Station" shared a link to the Golden-winged Warbler campaign on Experiment, encouraging its followers to support the project during its last few days (2017). 


\section{Analysis \& Results}

The Golden-winged Warbler project was a great success. The project reached its funding goal well before the campaign end date and was able to raise additional funds to purchase new equipment. The project page has not been active since the campaign's conclusion but once research commences on May 15, 2017, backers will likely see periodic field and data updates. As previously stated, the majority of backers registered for Experiment during the months the campaign was live (February and March), suggesting the project was primarily supported by those who had an outside connection to the researchers, independent of the crowdfunding platform.

When asked if using the crowdfunding platform helped disseminate their research, Roth enthusiastically replied

"YES, this is partly due to functions of this particular crowdfunding platform which allows for project updates (called lab notes) including use of photos and videos to provide donors with updates post-fundraising. We receive comments from many of our donors appreciative of the project updates posted to our project."

(A. Roth, personal communication, August 16, 2017) [See Appendix 5.3]

Buckhardt added,

"By sharing my research on such an accessible platform, it definitely reached a larger audience. I still have a link to the crowdfunding page at the bottom of all of my emails as a way for people to see what I am working on. I think the pictures and videos make it much more accessible and exciting to a broader audience than reading something as formal as a journal article.”

(A. Buckhardt, personal communication, August 17, 2017) [See Appendix 5.3] 
Though motive for support is difficult to assess, it can be determined that most backers had an interest in supporting the mission of this campaign and furthering research on this dwindling species.

\section{Discussion \& Conclusions}

Traditional sponsored research provides a conversation and presentation of research activities and outcomes at the publication and presentation level, and through established, traditional channels, such as peer-reviewed scholarly journals, and conferences. Crowdfunded campaigns broaden the audience for scientific research while utilizing social networking platforms such as Twitter and Facebook, and other non-scholarly channels. As it becomes "content" on social networking platforms, research finds a new, general audience (Ibrahim, et al., n.d., Key takeaways). Crowdfunded campaigns engage and "let in" the audience before publication, and the audience becomes involved with the activities, trials and outcomes of research.

Crowdfunding platforms include features and social media integration that enable researchers to communicate immediately and directly with an audience, and showcase a research project. Crafting a message that is clear and engaging, and packaging communications using social media such as Twitter, Facebook, and YouTube, greatly aid principal investigators in attracting supporters and sustaining support by engaging and interacting with them. A notable post from Eloise Mikkonen (2016) describes the connection between her selection as a finalist in the Finnish Innovation in Research Competition and her campaign, particularly the ways she communicated her research: 
The reason for my nomination was specifically related to my crowdfunding campaign on [Crowd.Science] and the supposedly novel way I communicated my Alzheimer's research to the public. The campaign involved a short video which I did in the lab, some written text and offering a few perks to people who supported my work from seminars to a simple postcard. As a result of the campaign I found that people were actually quite curious about my work and interested in what I had to say about it. Before the campaign I'd assumed that talking about my research with any level of details was likely to be a conversation killer!

Crowdfunding can play a positive role in promoting and facilitating open science and open access. The crowdfunding platform Experiment promotes open access for publications resulting from their campaign research outcomes. Experiment views open access as a principal of good science, and as a model for adding value to myriad scholarly communication materials, including: “... peer-reviewed journal publications, conference proceedings, academic posters, graduate theses, open data sets, and more" (Experiment, 2017, FAQ/ What is the reward for funding science?).

The relative scale of successfully funded campaigns to sponsored research is small. Crowd.Science has sponsored 27 campaigns since 2015 and successfully raised $£ 95,518$, while Experiment has had 691 successful campaigns and raised more than \$7,000,000 since 2012 . However, the profile, impact, and social currency of crowdfunded campaigns are potentially high. Reasons for this include: the novelty of crowdfunding draws media attention, campaigns' successful social media integration, passion and enthusiasm of supporters and their interest in directly supporting and participating in the research process, and, often, meaningful 
entrepreneurial and social or environmental activities -- the opportunity to do good and make a difference.

In order to make the most of the opportunity, scientists become performers and story tellers to an audience that may include non-scientists. In order to gain supporters they may need to describe their own research in ways that make it accessible and interesting, but not accessible to the degree that it isn't taken seriously (Ibrahim, et al., n.d., On science outreach). A successful campaign requires a lot of outreach and continual communication; some scientists may not have the time or find it burdensome.

Succeeding with crowdfunding isn't less work than securing grants funding. In the paper, Crowdfunding: Motivations and deterrents for participation, Gerber and Hui report that there is a varied amount of time spent on campaigns, but compared to preparing grant proposals choosing to crowdfund may prove to be more time consuming (Gerber \& Hui, 2013, p. 34:20).

Research crowdfunding facilitates dynamic connections between researchers and audience, and makes available to researchers a potentially enthusiastic group of supporters seeking to meaningfully participate in science. Researchers have found in crowdfunding the freedom to explore unexpected, creative interdisciplinary collaborations, and projects that actively realize social and environmental good. Through connections to supporters and the myriad social networking features of crowdfunding platforms, researchers have opportunities to communicate research activities, processes and outcomes in new dynamic ways through materials of research and scholarship that include more the traditional array of peer-reviewed articles, monographs, data and conference presentations. This new channel of communication includes public lab notes, online discussion, meetups, and creative multimodal scholarship and presentation of research. 



\section{Appendix: Data, platform overview, and personal communication}

\section{with investigators}

\subsection{Campaign Data}

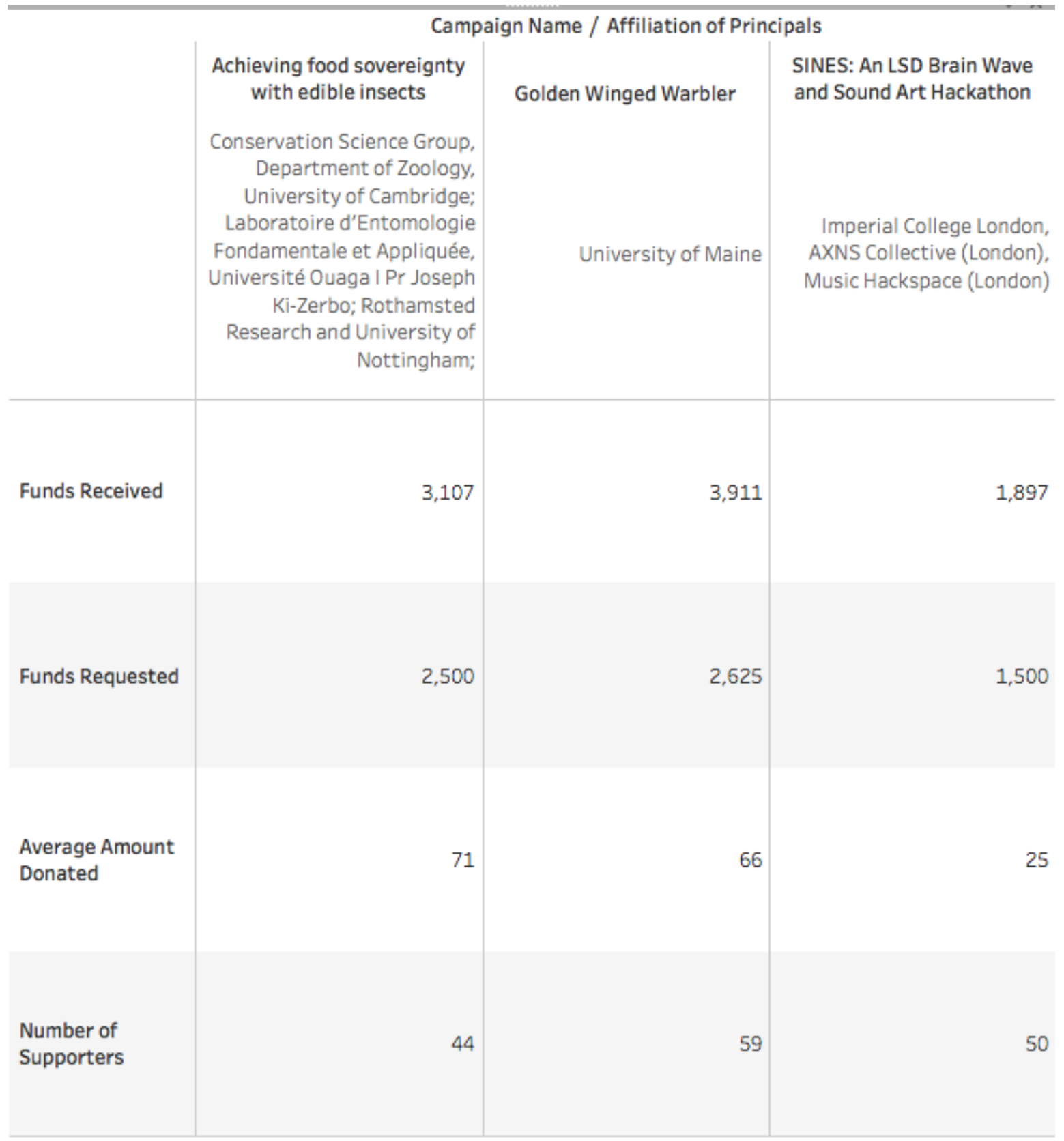




\section{Fig. 11: Crowdfunded research campaign data}

\subsection{Platform Overview}

\section{Experiment}

\section{Overview}

Experiment is an online crowdfunding platform for supporting scientific research. Launched in 2012 under the name Microryza (Quick, 2012), Experiment has since cultivated a 98,000 member community of scientists, researchers, and science-enthusiasts and supported 691 fully funded experiments since its inception (Experiment, FAQ). The for-profit company employs a team of reviewers to authenticate and approve each project before launch, ensuring its validity and scientific value. Every project must satisfy the following three criteria:

1. The experiment seeks to answer a specific scientific question.

2. The process and results can be shared openly and transparently.

3. The researchers have the expertise needed to meet the goals. (Experiment, Researcher Guide/ Project Criteria)

Additionally, reviewers may consider prior publications, presentations, or research to further authenticate an academic experimenter's credibility; and, if there are human or animal subjects involved, the academic scientists are asked "to show evidence of institutional support and review" which can include the institution's IRB or IACUC review process (Experiment, Researcher Guide/ Additional criteria for academic scientists). If the project is being conducted by a scientist independent of academia (i.e. high school students, citizen scientists, etc.), the scientist is encouraged to recruit public endorsements, provide evidence of the proper resources 
and their capacity to carry out the experiment, and offer an explanation as to why their project is important and unique.

According to the FAQ, Experiment promotes an open access model, encouraging experimenters to share their results and findings with the public, free of charge. Though the platform does not mandate each experimenter to do so, experimenters who have agreed to share their findings have an Open Access badge on their project. At the minimum, all fully funded projects are required to share the results with backers of that project. (Experiment, FAQ).

\section{Funding models and cost}

Like many crowdfunding sites, it is free to launch a project on Experiment. If the project is fully funded, platform and processing fees are applied at the end of the campaign. Projects successfully funded by academic researchers are not subject to institutional overhead. As of April 2017, there is a 5\% platform fee and a 3-5\% processing fee per successful backer card charge (Experiment, FAQ). The platform operates on an 'all-or-nothing' policy, meaning if a project does not reach its monetary goal, backers will not be charged and no processing or platform fees apply. As of September, 2018, Experiment has seen over \$8 million dollars pledged, and a $45.51 \%$ success rate (Experiment, Footer and FAQ).

Seeking funds for a project on Experiment is often done in lieu of applying for a grant. Alternatively, the funds could be used to support early-stage research or to supplement partially funded projects. Contributions are only tax-deductible when a project is affiliated with a 501(c)(3) organization; this affiliation is clearly marked on a campaign's description. Project cancellations are not permitted once a campaign has launched and all backers will be charged once a project has met its goal. As of April 2017, Experiment supports projects that receive funds in the United States, Canada, UK, and Australia (Experiment, FAQ). 


\section{Crowd.Science}

\section{Overview}

Crowd.Science (formerly Walacea.com) is a science research crowdfunding platform for researchers founded by Natalie Jonk in 2015 (Crowd.Science, About Us).

Crowd.Science markets itself as an opportunity for researchers to showcase their work and engage new audiences (Crowd.Science). Evidence of this opportunity is seen on the Crowd.Science blog. The blog features updates on campaigns and posts from Crowd.Science researchers.

For scientists, Crowd.Science (Crowd.Science, FAQ) outlines four significant differences between itself and other crowdfunding platforms:

1. Crowd.Science only accepts science projects, these can be scientific research or projects aimed at supporting outreach. So far we have only worked with scientists working at universities, however we are happy to accept projects from independent scientists or citizen scientists.

2. The rewards structure is geared towards outreach and more structured than other platforms. This means we can mentor you through the process and you can also discuss ideas with your peers who are crowdfunding their work. We are also investigating ways we can manage perks for you upon request so you can spend more time conducting research!

3. We help you plan how to target key audiences and market your campaign. This is a really key part of running a successful campaign and is often overlooked. Before we 
make your campaign live we advise you to map out key networks who you believe may be interested in your work and plan a communications strategy with them. You can find more guidelines through our crowdfunding tips blog and crowdfunding guidelines page.

4. We are in touch with a number of science correspondents for major news outlets and if your research is of media appeal we can help you reach out to journalists. So far scientists crowdfunding with us have been featured in Reuters, CNN, Sky News, BBC, IFLS, RT, Nature, Science News and many other outlets.

For supporters, Crowd.Science (Crowd.Science) outlines two significant differences that separate it from other crowdfunding platforms:

1. Crowd.Science only accepts science projects, these can be scientific research or projects aimed at supporting outreach. So far we have only worked with scientists working at universities, however we are happy to accept projects from independent scientists or citizen scientists. This means that on Crowd.Science you will only be able to fund and browse science projects.

2. The rewards structure is geared towards engaging people in science. This means through Crowd.Science you will have the opportunity to support science and learn more about it through seminars or artistic interpretations of the findings! We like offering unique artwork related to studies that fund on Crowd.Science!

\section{Funding models and cost}


Crowd.Science supports two funding models: flexible, and all or nothing. Flexible funding means that all funds raised are collected, provided that enough funds are raised for the scientists/principals to honor the affordances earned by supporters and also do at least part of the work detailed in the campaign. All or nothing funding is for the campaign that needs to meet or exceed its funding goal, and if it does not reach the goal, it cannot do the project or even a part of it. For the all or nothing campaign, not meeting the funding goal means that all funds are refunded to backers and no affordances are processed.

Crowd.Science charges $5 \%$ of the money raised by successful campaigns (including both flexible and all or nothing funding model campaigns). In addition, the payment processing service charges each campaign a fee of $3 \%$.

\section{General platform data}

Crowd.Science campaign data as of 04/29/2017

\begin{tabular}{|l|l|}
\hline Total campaigns & 27 \\
\hline Open campaigns & $11(40.74 \%)$ \\
\hline Successful campaigns & $10(37.04 \%)$ \\
\hline Not funded campaigns & $7(25.93 \%)$ \\
\hline Total funds raised & $£ 144,013$ \\
\hline Successful campaign funds & $£ 95,518(66.32 \%)$ \\
\hline Funds lost & $£ 9,029(6.27 \%)$ \\
\hline
\end{tabular}




\begin{tabular}{|l|l|}
\hline Open campaign funds & $£ 39,466(27.4 \%)$ \\
\hline
\end{tabular}

Table 1: Crowd.Science campaign data

\subsection{Personal Communication with Amber Roth and Aaron Buckhardt}

Amber Roth: This is tough to answer. Some grant proposals are short with little administration. Others are highly time-consuming. A good crowdfunding project will require considerable time to develop a thoughtful webpage and continual networking of the project to various networks of people. Regarding project development, a lot of time was dedicated to scripting the text and developing an attractive video (see later comments about messaging). A good "electronic ground game" is essential to reach a lot of people especially at project kick-off. Showing early success helps attract interest especially for a crowdfunding platform where projects can be ranked by fundraising activity and progress toward your funding goal. Also, we reached our initial goal early which allowed us to increase our fundraising goal to add a second component to the project (not all crowdfunding platforms have this feature). In short, a majority of the time commitment [sic] happens prior to the launch of the project. The other nice thing is that you know if you have the funds in 30 days (a much shorter timeline than most grant proposals)! (A. Roth, personal communication, August 16, 2017)

Anna Buckhardt: At this point in my career I don't have a ton of experience with grant writing and management. From the experience I do have, the initial preparation of the crowdfunding page was more time consuming than any grants I have written (mind you, 
the grant [sic] I have written have all been fairly small). I think that the management aspect of the crowdfunding page is comparable to grants, in that you have to give periodic updates on your research progress. The crowdfunding updates (termed Lab Notes on the Experiment page) are slightly more fun in my mind though, because they are less formal, blog-style updates with room for photos and videos. I think the other thing with the crowdfunding updates that is different is that I know there are individual people who are excited about my research who will be looking for updates. It's not just a grant of budget committee who's [sic] job it is to read a formal report. This aspect makes it easier to want to give research updates on the crowdfunding platform (and I'm very glad Experiment makes it so easy to give updates to funders).

(A. Buckhardt, personal communication, August 17, 2017)

\section{References}

AXNS Collective. (2017, March 15). Can you help us hit $£ 1900$ :) - nice perks left! [Facebook status update]. Retrieved from https://www.facebook.com/axnscollective/

AXNS Collective [AXNSCollective]. (2017, March 18). @ RobinCarhartHar opening our LSD Sound art - data-hackathon! \#sciart @ MusicHackspace @ SomersetHouse. [Tweet]. Retrieved from https://twitter.com/AXNSCollective/status/843036478334799872

Barilla Center for Food and Nutrition (2016). BCFN YES! Young earth solutions. Retrieved from https://www.barillacfn.com/en/bcfnyes2017/

Bedder, R., Carhart-Harris, R., Lorenz, R., Marcus, M., \& Stratton, R. (2017). SINES: An LSD brain wave and sound art hackathon. Retrieved from https://crowd.science/campaigns/lsd-brainwaveand-sound-art-hackathon/ 
Buckardt, A. (2017, March). 15 Days left! Please help me reach my stretch goal. Or at least learn a thing or two by checking out my page [Facebook status update]. Retrieved from https://www.facebook.com/anna.buckardt

Buckardt, A. (2017, February 16). Join the journey: Golden-winged Warbler Migration [Facebook status update]. Retrieved from https://www.facebook.com/lakecookaudubon/posts/10154650569039678

Buckardt, A. (2017, February 19). Join the journey: Golden-winged Warbler migration [Video file]. Retrieved from https://youtu.be/35tuFhf8hlA

Buckardt, A., Roth, A. (2017). Ask the scientists. In Experiment (Join the journey: Golden-winged Warbler migration). Retrieved from https://experiment.com/projects/join-the-journey-goldenwinged-warbler-migration\#ask-the-scientists

Buckardt, A., Roth, A. (2017). Budget. In Experiment (Join the journey: Golden-winged Warbler migration). Retrieved from https://experiment.com/projects/join-the-journey-golden-wingedwarbler-migration\#budget

Buckardt, A., Roth, A. (2017, February 22). Lab note \#1. In Experiment (Join the journey: Goldenwinged Warbler migration).Retrieved from https://experiment.com/u/MtKBpQ

Buckardt, A., Roth, A. (2017, February 25). Lab note \#2. In Experiment (Join the journey: Goldenwinged Warbler migration). Retrieved from https://experiment.com/u/GVQs0Q

Buckardt, A., Roth, A. (2017). Meet the team. In Experiment (Join the journey: Golden-winged Warbler migration). Retrieved from https://experiment.com/projects/join-the-journey-goldenwinged-warbler-migration\#team

Buckardt, A., Roth, A. (2017). Project backers. In Experiment (Join the journey: Golden-winged Warbler migration). Retrieved from 
https://experiment.com/projects/join-the-journey-golden-winged-warbler-migration\#prj-backers

Carhart-Harris, R. L., Muthukumaraswamy, S., Roseman, L., Kaelen, M., Droog, W., Murphy, K., \& Nutt, D. J. (2016). Neural correlates of the LSD experience revealed by multimodal neuroimaging. PNAS Proceedings Of The National Academy Of Sciences Of The United States Of America, 113(17), 4853-4858. doi:10.1073/pnas.1518377113

Crowd.Science. (2017, February 20). The LSD brainwave and sound art hackathon [YouTube video]. Retrieved from https://youtu.be/qfiUqEnL1ko

Crowd.Science. (n.d.). About Us. Retrieved from https://crowd.science/about-us-crowdfunding$\underline{\text { sciencel }}$

Crowd.Science. (n.d.). FAQ. Retrieved from https://crowd.science/faqs/

Eisfeld-Reschke, J., Herb, U., \& Wenzlaff, K. (2014). Research funding in open science. In Opening Science (pp. 237-253). Springer International Publishing.

Experiment. (n.d.). FAQ. Retrieved from https://experiment.com/faq

Experiment. (n.d.). Researcher Guide/ Project Criteria. Retrieved from https://experiment.com/guide/design\#review_criteria

Experiment. (n.d.). Researcher Guide/ Additional criteria for academic scientists. Retrieved from https://experiment.com/guide/design\#review_criteria

Gerber, E. M. \& Hui, J. (2013). Crowdfunding: Motivations and deterrents for participation. ACM Transactions on Computer-Human Interaction (TOCHI), 20(6), Article 34 (December 2013), 32 pages. http://dx.doi.org/10.1145/2530540

Ibrahim, D. M., Symmons, U., \& Lupiáñez, D. G. (n.d.). Getting Specific. In Experiment (Anatomy of a Lil Bubome: Case study, The LilBubome - Sequencing LilBub's Magical Genome). Retrieved from https://experiment.com/case_studies/lilbub 
Ibrahim, D. M., Symmons, U., \& Lupiáñez, D. G. (n.d.). On Science Outreach. In Experiment (Anatomy of a Lil Bubome: Case study, The LilBubome - Sequencing LilBub's Magical Genome). Retrieved from https://experiment.com/case_studies/lilbub

Ingeno, L. (2013). Crowdfunding Academic Research. Inside Higher Ed. Retrieved from https://www.insidehighered.com/news/2013/06/10/academic-researchers-using-crowdfundingplatforms

Jagatia, A. (2017). Are edible caterpillars the future of sustainable protein? Retrieved from http://www.bbc.co.uk/programmes/p04z7fbg

Kemp Natural Resources Station (2017, March 15). Just a couple days remain to support Anna Buckardt's project! [Facebook status update] Retrieved from https://www.facebook.com/kempnrs/

Marcus, M. (2013). AXNS Collective. Retrieved from http://axnscollective.org/

Michaels, D. (2017, March 3). [Facebook status update].

Mikkonen, E. (2016, August 2). Should scientists learn to pitch? [blog post]. Retrieved from https://crowd.science/should-scientists-learn-to-pitch/

Music Hackspace. (n.d.). About Us. Retrieved from http://musichackspace.org/about-us/

Office of the Vice President for Research, Stony Brook University. (2016). Sponsored Programs Activity Report, 2015 -2016. Retrieved from http://research.stonybrook.edu/sites/research.stonybrook.edu/files/sponsored-programsexpenditures-fiscal-2015-2016.pdf

Payne, C., Badolo, A., \& Dobermann, D. (2017). About this project. In Experiment (Achieving food sovereignty with edible insects: Breaking the cycle of poverty and malnutrition). Retrieved 
from https://experiment.com/projects/achieving-food-sovereignty-with-edible-insects-breakingthe-cycle-of-poverty-and-malnutrition

Payne, C., Badolo, A., \& Dobermann, D. (2017). Meet the Team. In Experiment (Achieving food sovereignty with edible insects: Breaking the cycle of poverty and malnutrition). Retrieved from https://experiment.com/projects/achieving-food-sovereignty-with-edible-insects-breaking-thecycle-of-poverty-and-malnutrition

Payne, C., Badolo, A., \& Dobermann, D. (2017). Team Bio. In Experiment (Achieving food sovereignty with edible insects: Breaking the cycle of poverty and malnutrition). Retrieved from https://experiment.com/projects/achieving-food-sovereignty-with-edible-insects-breaking-thecycle-of-poverty-and-malnutrition

Peterson, S., Streby, H., Kramer, G., Lehman, J., Buehler, D., \& Andersen, D. (2015). Geolocators on Golden-winged Warblers do not affect migratory ecology. The Condor, 117(2), 256-261.

Quick, Darren. (2012). Microryza brings crowd-funding to scientific research. New Atlas, Science. Retrieved from http://newatlas.com/microryza-crowd-funding-scientific-research/22147/

Tarkan. L. (2015). Why these startups want you to eat bugs. Fortune, Food Industry. Retrieved from http://fortune.com/2015/08/25/edible-insects-bug-startups/

Vachelard J, Gambarra-Soares T, Augustini G, Riul P, \& Maracaja-Coutinho, V. (2016). A guide to scientific crowdfunding. PLOS Biology, 14(2): e1002373. Retrieved from https://doi.org/10.1371/journal.pbio.1002373 